\title{
O Diálogo como uma Estratégia de Interação na Formação Docente na EAD
}

\author{
Rute Vera Maria Favero - IFRS/UFRGS - rute@ufrgs.br \\ Maria Lúcia Barbosa - PGIE/UFRGS - malukroeff@yahoo.com.br \\ Bárbara Ávila - FACED/UFRGS - Barbara@ cinted.ufrgs.br \\ Liane Tarouco - PGIE/CINTED/UFRGS - liane@ penta.ufrgs.br \\ Sérgio Roberto Kieling Franco - FACED/UFRGS - Sergio.franco@ufrgs.br
}

\begin{abstract}
Resumo. Este artigo mostra que interações dialógicas tornam possível a construção do conhecimento por parte de professores em cursos de formação continuada de docentes a distância, quando são utilizadas estratégias de interação que permitem conseguir uma melhor interação social e uma maior colaboração entre os sujeitos. Aborda também a importância do diálogo no processo da aprendizagem, visto sob as perspectivas freireana e piagetiana. Além disso, são analisadas as relações sociais, sob a luz da teoria de Vygotsky e sua influência na aprendizagem do sujeito. Os resultados iniciais apontam para a necessidade de estratégias de interação dialógica a serem utilizadas pelos mediadores que atuarão em cursos a distância.
\end{abstract}

Palavras chave: diálogo, EAD, interação, formação docente, estratégias de interação.

\begin{abstract}
This paper shows dialogic interactions make possible knowledge construction by teachers, in courses of continued formation of teachers at a distance, when interaction strategies are used which allow better social interaction and greater collaboration among subjects. We approach the the importance of dialog on the learning process, under freirean and piagetian perspectives. Social relations are also analysed, as in Vygotsky theory, and their influence over subjects' learning. Initial results point to the needing of dialogic interaction strategies to be used by mediators who are going to work on distance education courses.
\end{abstract}

\section{Introdução}

Cada vez mais pessoas se comunicam virtualmente e participam de atividades que ocorrem no espaço virtual denominado ciberespaço, ou seja, "um lugar onde se vai com a mente, catapultada pela tecnologia, enquanto o corpo fica para trás" (Gibson, 2003). Para Lemos (2002), "mais do que um fenômeno técnico, o ciberespaço é um fenômeno social". E é nesse fenômeno social que se formam redes de máquinas e pessoas que se comunicam e criam uma matriz da vida real, potencializada na vida virtual através dessas comunidades virtuais, possibilitando a construção social do conhecimento, mediada por computadores.

Sabe-se que o uso crescente da tecnologia tem contribuído para mudanças nas estratégias de ensino e aprendizagem, tornando-se necessário capacitar os professores para realizar seu trabalho com competência e conscientes de que vivem em um mundo onde diversos meios podem levar ao raciocínio e ao conhecimento. Então, faz-se 
importante a formação de cidadãos capazes de produzir e interpretar as novas linguagens do mundo atual e futuro.

Quando um educando, mesmo sendo um professor, mantém uma interação dialógica com seus colegas, ou com seus professores ou tutores, há aquisição mútua de conhecimento (Favero e Franco, 2007). Partindo-se do princípio que diálogo não é permuta ou simples troca, mas sim uma revelação dos interlocutores, o que ocorre entre os educadores e educandos, numa comunidade virtual, é essencial e pode contribuir para uma maior geração de conhecimento. A utilização de estratégias de interação, por parte do tutor, estimula os educandos a interagirem e se comunicarem com os outros participantes.

Portanto, este artigo objetiva mostrar que ao se utilizarem estratégias de interação específicas à formação de relações sociais, é possível a geração de conhecimento por parte dos participantes de cursos na modalidade a distância, oferecidos nos Ambientes Virtuais de Aprendizagem (AVAs). Inicialmente, a seção 2 define o que é diálogo a partir das perspectivas freireana e piagetiana. A seção 3 apresenta uma síntese da importância das relações sociais e da mediação, sob a luz da teoria de Vygotsky. Na seção 4, pode-se entender a análise feita através de um curso a distância oferecido através do Ambiente Moodle, que permite uma maior interação dialógica. Na seção 5, encontram-se os trabalhos relacionados e na seção 6, as considerações finais.

\section{O diálogo nas perspectivas freireana e piagetiana}

A função do professor/tutor é propiciar situações que permitam a interação entre ele e os educandos e entre os educandos entre si. O diálogo é um processo coletivo e que também pode ocorrer em comunidades virtuais, utilizando-se uma linguagem específica através de textos escritos em fóruns, diários, e-mails, etc.

Tanto para Freire (2004), quanto para Piaget (1973), um sujeito não aprende sozinho, mas sim a partir do momento que executa algo cooperativamente na relação com o outro, onde esses sujeitos podem dialogar na busca de um novo conhecer, fortalecendo as trocas que ocorrem. Paulo Freire (2003) diz que o diálogo é condição essencial para a formação da consciência crítica e é construído na relação "entre sujeitos mediatizados pelo mundo". Para Piaget (1973), a aprendizagem se dá a partir da assimilação e acomodação, gerando a equilibração, sendo que também pode ocorrer um novo desequilíbrio, onde tudo se inicia novamente. Para que isso ocorra é necessário que o sujeito interaja com o objeto e com os outros sujeitos de seu conhecimento. Na interação entre estes, constrói-se o conhecimento.

Com base nas concepções freireana e piagetiana, pode-se estabelecer categorias que permitem definir o que é diálogo, tais como: cooperação, equidade na relação, geração de conhecimento, incentivo e participação contínua (Freire, 2004) (Piaget, 2002), e que serão descritas a seguir.

A cooperação ocorre quando os interlocutores passam a se ajudar mutuamente objetivando um fim comum, portanto, sempre que se identifica que os sujeitos estão se ajudando e colaborando entre si e ajudando e colaborando com o grupo, considera-se que os mesmos podem estar envolvidos no que definimos como sendo diálogo, desde que estejam ocorrendo, simultaneamente, também as outras categorias. 


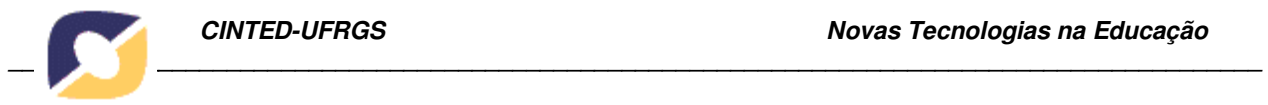

Equidade na relação é identificada nas interações que ocorrem quando os sujeitos se envolvem numa relação de respeito mútuo com deveres e obrigações de um lado e direitos, compensações e retribuições de outro, mantendo uma horizontalidade na relação. Diálogo não é dominação e numa comunicação dialógica não pode haver egocentrismo e tampouco relações de coação, mas sim equilíbrio nas trocas (Piaget, 2002).

Entende-se por geração de conhecimento sempre que, numa ordem temporal, aparecer um nível de explicitação sobre um determinado tema e depois isso passar a aparecer numa estruturação mais complexa, permitindo reconhecer que o educando conseguiu um melhor entendimento do que estava sendo exposto durante o curso ou quando, por depoimento, o aluno admitir que aconteceu conhecimento, devido à colaboração dos outros. Para Paulo Freire (2003), dialogar significa manter uma conversa que gera conhecimento para todas as pessoas que estejam envolvidas. Além disso, acrescenta que "a relação dialógica - comunicação e intercomunicação entre sujeitos, refratários à burocratização de sua mente, abertos à possibilidade de conhecer e de mais conhecer - é indispensável ao conhecimento" (Freire, 2004).

Incentivo é o que ocorre quando os interlocutores (educandos e educadores) incentivam seus colegas ou alunos a continuarem a participar do curso, interagindo e realizando as tarefas solicitadas no mesmo, indicando-lhes a importância da participação e continuidade dos mesmos para o sucesso de todo o processo.

Já a participação contínua leva em conta a contiguidade de interações que podem ser efetuadas pelos alunos durante a realização do curso, considerando-se a participação desde o inicio ao fim do mesmo em todas as ferramentas ofertadas e independente do tipo de interação que ocorra.

\section{Interação social e contribuições para a aprendizagem, segundo Vygotsky}

Para Vygotsky (1998), as trocas que ocorrem na interação do sujeito com seu meio, principalmente seu meio social e cultural são fundamentais para a aquisição de conhecimento. O princípio do desenvolvimento humano se baseia numa inter-relação entre o meio social e as bases biológicas. Considera-se, portanto, essa relação dialética a partir do momento em que o meio afeta o indivíduo, provocando mudanças que serão refletidas novamente no meio. Além disso, Vygotsky (1998) defende a idéia de que o desenvolvimento da inteligência é produto da convivência do ser humano com seus semelhantes em um ambiente impregnado pela cultura, uma vez que o homem só se constrói na presença do outro. É através da intermediação dessas pessoas que o rodeiam que o sujeito absorve as informações do meio, que sempre se apresentarão carregadas de significados sociais e históricos, ou seja, carregados de significações culturais adquiridas na convivência.

Neste estudo específico, o enfoque se dá na interação que pode acontecer em cursos a distância oferecidos num AVA. Portanto, relaciona-se a uma interação mediada por computador que enfatiza as relações sociais e permite interações dialógicas entre os participantes através de ferramentas disponibilizadas pelo próprio AVA, como chat, fórum e correio, além de uma linguagem específica onde são aceitos, por exemplo, emoticons (-)). Segundo Aronson et al (2002), "a jóia da coroa da comunicação nãoverbal é o canal das expressões faciais", sendo que as expressões primárias mais comuns como alegria, tristeza e raiva são universais, portanto a utilização dos emoticons 
que conseguem expressar essas emoções podem ser utilizados e serão interpretados por todos com igual precisão. A mediação é simbólica, isto é, o sujeito pode se utilizar de signos e ferramentas para estabelecer uma relação entre ele e o objeto de conhecimento, sendo que a linguagem é um dos signos utilizados como agente mediador, além de ser um dos elementos essenciais da interação humana conseguida através da cooperação social mediada por instrumentos (Vygotsky, 1998).

A principal função da linguagem é a de intercâmbio social, isto é, para se comunicar com seus semelhantes o homem cria e utiliza sistemas de linguagens. Essa troca que ocorre entre o sujeito e o meio, que pode ser o próprio ambiente, ferramentas específicas ou outro sujeito, possibilita o processo da aprendizagem. O processo de transformação da aprendizagem de um processo que inicia social (externo) e vai tornando-se individual (interno), é chamado de internalização ou apropriação (Passerino \& Santarosa, 2000). O sujeito não é apenas ativo, mas interativo, porque forma conhecimentos e se constitui a partir de relações intra e interpessoais.

Para uma melhor compreensão do processo da passagem de um nível para outro, Vygotsky (1998) desenvolveu o conceito de Zona de Desenvolvimento Proximal (ZDP), que definiu como sendo a "distância entre o nível de desenvolvimento real, que se costuma determinar através da solução independente de problemas, e o nível de desenvolvimento potencial determinado através da solução de problemas sob a orientação de um adulto ou em colaboração com companheiros mais capazes". Pode-se dizer que quando o sujeito consegue resolver os problemas sozinho, ele está no nível de desenvolvimento real, porém quando ele precisa da orientação de outro sujeito, que pode ser o professor ou um colega mais experiente, para resolver os problemas, ele se encontra na ZDP. Portanto, a aprendizagem ocorre quando o sujeito está inserido numa comunidade ou num grupo social, onde aprende primeiro o que o grupo produz, para só depois internalizar esse aprendizado.

\section{A sala de aula virtual: espaço da pesquisa e análise}

Para verificar se ocorre a construção do conhecimento, ou seja, a passagem de um nível menor de conhecimento para um nível maior, em cursos de formação de docentes oferecidos na modalidade a distância, foi analisado um curso que foi oferecido no ambiente Moodle, cujo objetivo era o aprendizado no próprio ambiente virtual de aprendizagem. Foram analisadas as interações ocorridas nos fóruns de dúvida e social, além de terem sido analisadas as interações mantidas entre os alunos e a tutora, no diário de bordo. A análise foi realizada em duas turmas e com 36 alunos que tiveram participação efetiva no curso, enviando e respondendo e-mails, respondendo aos fóruns, postando no mural, diário de bordo e portfólio. As ferramentas disponibilizadas no curso que permitiam uma interação aluno $\Leftrightarrow$ aluno e aluno $\Leftrightarrow$ professor foram chat, fórum, mensagens internas, diário, blog e videoconferência. O curso tinha duração de $20 \mathrm{~h}$ e podia ser realizado num período de 30 dias.

Os dados coletados para a análise advieram das interações realizadas entre os participantes durante o período do curso, considerando-se quando ocorriam diálogos e levando-se em conta a concepção de diálogo pregada por Paulo Freire e Jean Piaget.

A metodologia empregada permitiu alcançar maior compreensão do caso pesquisado e escolher um foco mais preciso para averiguação dos dados coletados. Sempre que, nas interações (textos escritos), foram percebidas ocorrências de diálogo, 
estas foram separadas para análise posterior, onde as mesmas seriam avaliadas segundo as categorias que foram estabelecidas a partir da revisão teórica realizada.

Cada aluno que ingressava no ambiente do curso recebia as boas-vindas da tutora, sendo esta a primeira estratégia de interação adotada, onde os mesmos eram estimulados socialmente e convidados a acessarem os recursos disponibilizados, além de serem convidados a adicionarem uma foto no perfil e a falarem um pouco de si próprios. A maioria dos alunos provinham da área de Ciências Humanas.

Muitas são as estratégias que podem ser adotadas por um professor/tutor em cursos a distância onde existam grupos sociais, a fim de que o desempenho do grupo seja o mais alto possível. Segundo Tarouco e Favero (2008), uma das estratégias de interação a ser utilizada na EAD é permitir que se estabeleçam laços pessoais, da mesma forma que acontecem nas aulas presenciais e, para transpor essa barreira, é interessante disponibilizar um fórum social, onde os alunos falem sobre si e discutam assuntos que não estejam relacionados com o tema das aulas. O tutor deve estimular os alunos a utilizarem os fóruns.

Para este estudo, foram criados dois fóruns no ambiente do curso, denominados Fórum de Dúvidas e Fórum Social. No fórum de dúvidas os alunos deveriam postar todas as dúvidas que surgissem referentes aos conteúdos disponibilizados no curso, sendo que essas dúvidas poderiam ser esclarecidas pela tutora ou por eles mesmos, e no fórum social eles poderiam postar assuntos diversos, isto é, seria um espaço para reflexão sobre assuntos variados. Deve-se salientar que não gerenciar um fórum é como sair de uma sala de aula, deixando os alunos numa situação de completo abandono, portanto, essa é uma estratégia que deve ser seguida pelo tutor, com muito rigor.

Entretanto, todas as participações interativas foram acompanhadas pela professora-tutora, que utilizou estratégias de interação com o intuito de estimular a participação dos alunos, tanto para realizarem as atividades propostas no curso, quanto para que se manifestassem e dialogassem com todos os participantes de sua turma. A análise realizada nas interações mantidas objetivava verificar se ocorre a construção do conhecimento em cursos de formação de docentes oferecidos na modalidade a distância. E confirmou-se com essa análise que, quando um AVA permite interações entre os próprios educandos e entre educandos e educadores, é possível que ocorra o diálogo entre esses sujeitos. Desde que os alunos sejam instigados, eles respondem ativamente e passam a participar efetivamente, cooperando com os colegas, incentivando-os e também, desenvolvendo-se intelectualmente.

Como exemplo, tem-se um aluno que iniciou um tópico, dissertando sobre a interação na EAD. Abaixo está parte do diálogo mantido pelos alunos e tutora, que gerou muitas postagens neste mesmo tópico e a discussão sobre este assunto foi levada para outros momentos de interação, inclusive síncrona, como o chat:

Aluno 5: Fiz um curso via internet onde a tutora não participou em nenhum momento. Não houve interação, ocorrendo um silêncio virtual, o que ocasiona um desestímulo geral.

Tutora: Escrevi noutros fóruns a respeito desse assunto, onde coloco que para que o aluno não se sinta só, deve haver interação entre estes atores que fazem parte de um curso a distancia e que é possível haver afetividade e é possível demonstrá-la nos textos que são escritos (eu prefiro dizer falados, pois o que postamos num AVA, ou em comunidades virtuais é a fala em forma de texto escrito).(...) E, de fala em fala, a gente vai descobrindo o outro e vai conseguindo se "abrir" mais, vai se mostrando mais, sendo que, nesses casos, a

V. $7 \mathrm{~N}^{\mathrm{o}} 3$, dezembro, 2009 
recíproca geralmente é verdadeira. E a pessoa retorna para "una parola di più", retorna para continuar mantendo esta ligação com outrem q está distante. Quanto distante? Geograficamente podem ser $\mathrm{km}$ e $\mathrm{km}$, mas a distância percebida pelo sujeito que está interagindo é a de si próprio em relação ao monitor. Esta é a sensação que permeia a gente.

Aluno 5: Gostei muito do texto sobre o diálogo. Concordo com você sobre a importância da conversa nos cursos a distância. Acredito que o tutor tem o papel de fazer essa "animação" no ambiente, mobilizar alunos para a interação coletiva com outros alunos e seus professores. O Tutor, dentre as inúmeras habilidades que deve ter, destaco o poder de mediação.

Aluno 6: oi Aluno 5, concordo plenamente com você. Também tive esta experiência, num curso de EAD a tutora não entrava em contato conosco. Foi tão desestimulante que a evasão foi enorme! Inclusive eu 3 . Ser mediador, ser incentivador, ser estimulante, ser cativante... Estas são algumas das habilidades que um tutor deve ter.

Ao interagir com os alunos em interações dialógicas, a partir da visão de Vygotsky (1998), o tutor estimula a construção de interações entre as ZDP, que são criadas à medida que os diferentes pontos de vista se integram e se confrontam, possibilitando a aprendizagem.

Ao perceberem que existia o fórum social e ao serem estimulados a participarem, muitos alunos decidiram manter um contato com os demais colegas. $\mathrm{Na}$ Turma 1 foram totalizadas 117 participações em 23 tópicos e na Turma 2, 80 participações em 31 tópicos, considerando-se somente as participações dos alunos e não as da tutora. O fórum social permitiu que os alunos se sentissem mais desinibidos, dando-lhes coragem para postar suas dúvidas, seja no fórum de duvidas, onde os colegas teriam contato ou em seu diário, diretamente para a tutora, ou ainda através de mensagens individuais enviadas à tutora. Além de postarem dúvidas, os alunos passaram a responder esclarecendo às duvidas colocadas pelos colegas. Para que os alunos postassem suas dúvidas no fórum de dúvidas, foi necessário salientar o quanto isso poderia ser benéfico a todos, uma vez que tanto a questão que representava uma dúvida, quanto à resposta, poderiam servir aos colegas, caso manifestassem a mesma dúvida. Isso surtiu efeito. Na Turma 1 foram totalizadas 118 participações em 38 tópicos e na Turma 2, 192 participações em 73 tópicos, conforme demonstra a Tabela 1.

\section{Gráfico 1 - Participação dos 36 Alunos em Fórum Social e Fórum de Dúvidas}

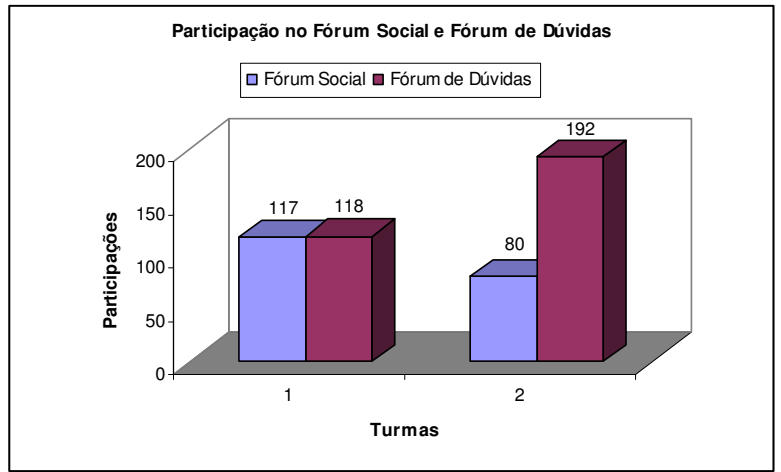

Pelo Gráfico 1, pode-se observar que dos 36 alunos com participação efetiva, os da Turma 1 mantiveram uma similaridade de participação tanto para o fórum social, quanto para o fórum de dúvidas (117 - 118 participações, respectivamente). Já os alunos da Turma 2, não obtiveram tanta participação no fórum social, porém postaram 
muitas dúvidas no fórum dedicado a responder essas questões. Algumas participações dos alunos no fórum de dúvidas estão descritas abaixo, onde se pode ver que estão sendo colocadas dúvidas e os próprios alunos estão respondendo. Não estão sendo colocados exemplos de respostas dadas pela tutora:

Aluno 7: Como faço para colocar títulos nas caixas (box) que quero criar?

Aluno 8: oi Daniela! Pelo que eu já naveguei no ambiente, só é possível acrescentar as caixas disponíveis no ambiente.

Aluno 2: eu também percebi isto. Não é possível acrescentar novas caixas com outros títulos.

Outro diálogo também no fórum de dúvidas:

Aluno 9: Estou fazendo as atividades, mas percebi que não estou enviando para o local certo. Já percebi que tem uma em cada canto... e agora?

Aluno 6: Oi, Aluno 9! Dê-me um exemplo do que está acontecendo para poder te ajudar. Não sei se está falando da "Oficina" ou das atividades realizadas no "Curso". Parece-me que está falando da "Oficina", se é lá você tem como mover suas atividades todas para o local certo... só me localize em seu problema.

Aluno 9: Olá, Aluno 6! Obrigada pelo apoio. Eu até já abandonei aquelas questões e estou fazendo-as novamente, agora os acertos são mais freqüentes.

Analisando as várias interações que ocorreram no curso, percebe-se que o aluno aprende junto com seus colegas, no seu grupo social, e não somente com a ajuda do tutor, isto é, ele não é tão somente o sujeito da aprendizagem, mas aquele que aprende junto ao outro também. Com isso, torna-se mister a adoção de estratégias para promover uma melhor interação e uma maior colaboração entre os participantes de cursos EAD, para que os mesmos se sintam integrados à comunidade virtual, criando laços sociais mais perenes, o que auxilia, inclusive, na redução da evasão em cursos nesta modalidade (Favero \& Franco, 2006). A função do tutor é a de orientar os alunos e a servir de guia, de forma a oferecer o devido apoio cognitivo. Deve também ser capaz de interferir na ZDP de cada aluno, provocando avanços não ocorridos espontaneamente.

A análise realizada no Diário de Bordo das duas turmas indica que aproximadamente $60 \%$ dos alunos que postaram seus relatos, manifestaram que ocorreu aprendizagem. Esses alunos, na sua grande maioria, foram os que também participaram ativamente dos fóruns. Deve-se levar em conta que nem todos que postaram no diário passaram a entender determinado conteúdo no qual apresentavam dúvidas. Abaixo alguns exemplos de postagens dos alunos, onde eles manifestam explicitamente o quê aprenderam.

Aluno 1: Agora estou conseguindo realizar alguma coisa e estou entendendo este monte de informações. Acabei de ler na seqüência os Procedimentos básicos e o Glossário, e também realizei as atividades. Antes estava perdida porque clicava em todos os lugares ao mesmo tempo e não entendia a lógica de tudo.

Aluno 2: 16/5 - Hoje refiz algumas atividades e insisti com outras do glossário, mas não consegui. Esse ambiente ainda é misterioso para mim.

Dia 06/06 - Bem, ao final deste curso, quero dizer que o susto do início foi substituído por uma sensação de capacidade, fundamental para todo ser humano. Que bom que eu não podia desistir... Portanto provei a mim mesma que era capaz. Uma dificuldade foi compreender o que a tutora falava com relação a: Este espaço é de vocês... escolham um tópico... treinem, etc. Quando aprendi a apertar o botão editar edição... aí... tudo clareou!!!

Aluno 3: 16 Jun 2008 - Confesso que o grande aprendizado é realmente a construção deste conhecimento coletivo que realizamos aqui, que não é igual em

V. $7 \mathrm{~N}^{\mathrm{o}}$ 3, dezembro, 2009 
nenhum outro curso do mundo porque é muito particular deste grupo. E acredito que não há como mensurar ou certificar esse aprendizado. Nem deveria...

Partindo-se das categorias de diálogo definidas nas perspectivas freireana e piagetiana, pode-se dizer que ocorreram interações dialógicas em $70 \%$ das interações mantidas pelos alunos participantes das duas turmas (Gráfico 2). Estão sendo considerados participantes todos os alunos que postaram em alguma das ferramentas de comunicação, pelo menos uma vez. Além disso, a pesquisa apontou que $81 \%$ dos alunos que tiveram participação ativa no ambiente e mantiveram interações dialógicas, obtiveram um crescimento na sua aprendizagem (Gráfico 2), contrapondo-se ao trabalho de Oliveira (2006), descrito na próxima seção.

\section{Grpáfico 2 - Percentual de Interações Dialógicas e de Melhoria na Aprendizagem}

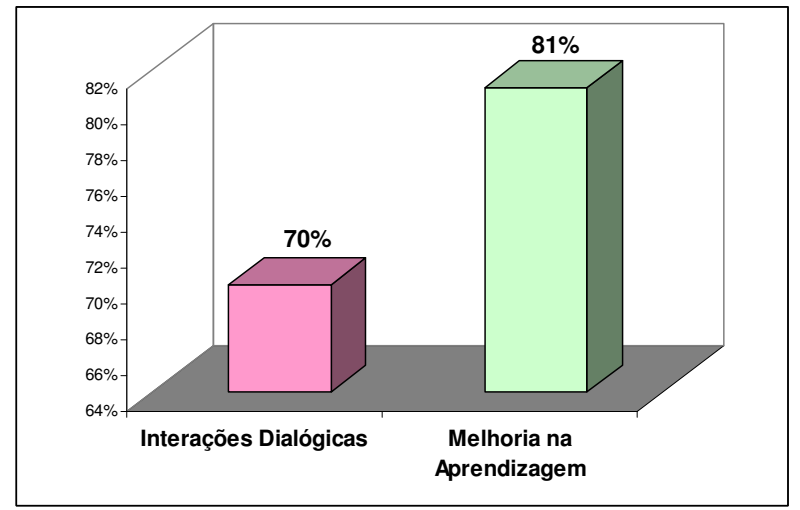

\section{Trabalhos Relacionados}

Oliveira (2006) analisou a utilização de um ambiente virtual de aprendizagem (AVA) como apoio ao processo de ensino e aprendizagem para a disciplina presencial de Gestão da Inovação, oferecida aos alunos do curso de Administração de Empresas da Faculdade de Economia, Administração e Contabilidade de Ribeirão Preto da Universidade de São Paulo. A pesquisa se baseou no ambiente educacional Teleduc, porém integrando-se alguns recursos multimídias, com o apoio de um mapa conceitual. O método utilizado foi um estudo de caso, utilizando-se da técnica de entrevistas em profundidade que possibilitou um melhor conhecimento do problema estudado. Alguns pontos merecem atenção e contrapõem-se com os descritos nas seções anteriores deste artigo, tais como: os alunos do estudo de Oliveira entendem que apenas o ambiente virtual de aprendizagem em si pode não ser tão útil quando utilizado sem o ensino presencial. Além disso, foi diagnosticada uma total falta de comunicação entre eles, que apontaram como sendo as principais causas a falta de tempo e a falta de estímulo. Outra questão a ser levantada é em relação à baixa frequência dos alunos em tópicos de interesse, que pode ser explicada em virtude da constante comunicação estabelecida pelo professor/tutor. Constata-se que essa postura pode ser preocupante, uma vez que não estimula os alunos a interagirem entre si, nem a buscar o cumprimento de suas 
próprias obrigações. Um fator de concordância entre os dois estudos é em relação às ferramentas que tornam possível a identificação do interesse do aluno e permitem verificar momentos de fraca demanda, dando a oportunidade de desenvolver soluções que motive os alunos a acessarem com mais frequência o ambiente.

Caldeira (2006) aborda questões pertinentes a métodos e práticas da modalidade presencial que são ampliadas quando se discute a modalidade online, na medida em que esta última traz novos aspectos ao cenário já existente. Considera que os ambientes digitais de aprendizagem apresentam características que o qualificam como um novo contexto educacional, diferente do presencial. Por isso, há necessidade de se criarem novos processos e estratégias que respondam a essas novos modelos, uma vez que a tecnologia pode sim potencializar uma proposta bem elaborada, mas, por si só, não é capaz de garantir desenvolvimento e aprendizagem. No estudo realizado neste artigo, comprova-se essa questão, mostrando-se a importância das interações dialógicas durante a aprendizagem online.

\section{Considerações Finais}

A contribuição deste artigo está na sua utilidade para todos que têm interesse pela EAD, devido à possibilidade de aumentar a quantidade de alunos que efetivamente aprendem nessa modalidade de educação e também devido a diminuição da evasão, utilizando-se estratégias específicas de interação. As ferramentas de interação existentes nos AVAs devem ser utilizadas pelo tutor de modo a ensejar uma maior comunicação entre os integrantes do curso. Uma boa acolhida ao ambiente desses cursos feita pelo tutor é fundamental para que os alunos percebam que serão parte importante deste processo. É dever do tutor instigar uma participação ativa dos alunos nessas ferramentas, fazendo uso das estratégias de interação. Dentre as várias estratégias de interação, o tutor pode usar o método socrático fazendo perguntas com o objetivo de ajudar o processo de aprendizagem ou utilizar um sistema de indicadores proposto por Araujo e Lucena (2005). Assim, possibilitará a ocorrência da cooperação entre os alunos no processo de ensino e aprendizagem, onde, entre outras coisas, o aluno terá a possibilidade de adquirir conhecimento, através da interação com o grupo e desenvolvendo a sua ZDP.

Pode-se comprovar, através da análise feita, que num curso a distância oferecido num AVA, o aluno promove sua aprendizagem quando se relaciona com $o$ professor/tutor e com os colegas, através das ferramentas disponibilizadas no ambiente, em que a linguagem escrita pode ser o centro do processo educacional. Para ter mais garantias de que o aluno vá adquirir essa aprendizagem, o professor, como agente mediador (por meio da linguagem ou outras ferramentas), deve levar em conta as potencialidades desse aluno (sujeito), que ao entrar em contato com uma pessoa mais experiente (professor ou colegas), poderá ter um maior avanço no desenvolvimento cognitivo.

Conforme pode ser visto nos estudos realizados pelas perspectivas freireana e piagetiana e, também, por uma análise da teoria de Vygotsky no que diz respeito à interação social e sua contribuição no processo de aprendizagem, foi possível observar nas turmas analisadas que uma mediação mais clara e intensiva estimula os alunos a participarem mais e a instigarem seus próprios colegas para que participem ativamente também. Essas observações continuam acontecendo em cursos na modalidade a distância nos quais os autores atuam, a fim de subsidiar novas pesquisas. 
Referências Bibliográficas

ARAUJO, L. LUCENA, G. Comunidades virtuais de aprendizagem: novas dinâmicas de aprendizagem exigem novas formas de avaliação. XVI Simpósio Brasileiro de Informática na Educação. SBC/UFJF. Juiz de Fora - MG, 2005.

ARONSON, E.; WILSON, T.; AKERT, E. Psicologia social. LTC. 3a edição Rio de Janeiro, 2002.

CALDEIRA, Ana C. Muscas; SILVA, Marcos; SANTOS, Edméa. Avaliação da Aprendizagem na Educação Online: uma experiência do MiniWeb Cursos. P. 461 - 470. Ed. Loyola. São Paulo,SP, 2006.

FAVERO, Rute V. M. Dialogar ou evadir: Eis a questão!: Um estudo sobre a permanência e a evasão na Educação a Distância, no Estado do Rio Grande do Sul. 2006. Porto Alegre: UFRGS, 2006. 169 p. Dissertação de Mestrado.

FAVERO, Rute V. M.; FRANCO, S. R. K. Um estudo sobre a permanência e a evasão na Educação a Distância. RENOTE. Revista Novas Tecnologias na Educação, $v$. 4, p. 2, 2006.

FAVERO, Rute V. M.; FRANCO, S. R. K. As categorias que definem a ocorrência de dialogo em Ambientes Virtuais de Aprendizagem. RENOTE. Revista Novas Tecnologias na Educação, v. 5, p. 1, 2007.

FREIRE, P. À sombra desta mangueira, São Paulo: Olho D'Água, 4 a edição, 2004.

FREIRE, P. Pedagogia do Oprimido, São Paulo: Paz e Terra, 36a edição, 2003.

GIBSON, William. Neuromancer, São Paulo: Aleph, $3^{\text {a }}$ edição, 2003.

LEMOS, André. Cibercultura: tecnologia e vida social na cultura contemporânea. Porto Alegre: Sulina, 2002

TAROUCO, Liane; FAVERO, Rute; MEZZARI, Adelina; ÁVILA. Bárbara; CABRAL, Roberto; BULEGON, Ana. Fatores que afetam a performance da comunicação mediada por computador. RENOTE. Revista Novas Tecnologias na Educação, v. $6 \mathrm{~N}^{\mathrm{o}} 2,2008$.

OLIVEIRA, João P. L. Ambientes Virtuais de Aprendizagem e mapas conceituais: um estudo exploratório com alunos do curso de administração de empresas da FEARP/USP. Universidade de São Paulo, USP, Brasil. Dissertação de Mestrado em Administração. 2006.

PASSERINO, Liliana M.; SANTAROSA, L. Costi. Uma Visão Sócio-Histórica da Interação dentro de Ambientes Computacionais. In: V Congresso Ibero-Americano de Informática na Educação - RBIE 2000, Viña del Mar - Chile.

PIAGET, J. Estudos sociológicos, Rio de Janeiro: Forense, 1973

PIAGET, Jean. Epistemologia genética. 2a Edição. São Paulo: Martins Fonte, 2002.

VYGOTSKY, L. S. Formação Social da Mente. $6^{\circ}$ Edição.- São Paulo: Martins Fontes, 1998. 